\title{
A Simple Assessment of the Global Long Term Supply of the Rare Earth Elements by Using a System Dynamics Model
}

\author{
Dejene Kifle ${ }^{1}$, Harald Sverdrup ${ }^{2}$, Deniz Koca ${ }^{2} \&$ Grethe Wibetoe ${ }^{1}$ \\ ${ }^{1}$ Department of Chemistry, University of Oslo, Norway \\ ${ }^{2}$ Applied Systems Analysis and System Dynamics Group, Department of Chemical Engineering, Lund \\ University, Lund, Sweden \\ Correspondence: Dejene Kifle, University of Oslo, Norway. Tel: 47-9061-8579. E-mail: \\ dejene.kifle@kjemi.uio.no
}

Received: October 8, 2012 Accepted: December 13, 2012 Online Published: December 30, 2012

doi:10.5539/enrr.v3n1p77

URL: http://dx.doi.org/10.5539/enrr.v3n1p77

\begin{abstract}
Our simple dynamic-simulation model shows that the global supply of Rare Earth Elements is limited for meeting the future demands of new technologies. Unless improved recycling policies are adapted strategic elements may become scarce in the next half-century as a result of a "peak Rare Earths Elements" phenomenon. The model results also show that the market alone cannot solve the resource-inefficiency problem because the market's instant and opportunistic nature impedes the long-term planning that is needed. Market mechanisms will only function if governments discourage wasteful practices by requiring recycling and long-term planning as conditions for the industry before the resource becomes too scarce. We conclude that technologies and industrial capacity for effectively recycling Rare Earth Elements will be in demand, and that effective recycling policy should be put in place soon to make the supply sustainable over the long-term.
\end{abstract}

Keywords: rare earth elements, sustainable supply of rare earth elements, recycling, system dynamics modelling, global supply, long term supply

\section{Introduction and Background}

The prospect of running out of oil and coal (Aleklett, 2003; 2007; Hirsch et al., 2005; Hubbert, 1982; Ragnarsdottir et al., 2011a; Sverdrup \& Ragnarsdottir, 2011) has become a reality with no easy escape, which has put a sharp focus on the resources necessary for developing new ways of generating, transforming and using energy. We live in a time of significant and recent change (Ragnarsdottir et al., 2011a). Never has the earth had as many people living as now and never has the extraction and use of resources been greater (Beder, 2000; Costanza \& Daly, 1992; Daily \& Ehrlich, 1992; Evans, 1998; Gordon et al., 2006; Meadows et al., 1972; 2002). Globalization has brought possibility for wealth, health and education to largest-ever number of people, who are also participating in the resultant rise in consumption (Meadows et al., 1972; 2002; Turner 2008). As humans now are slowly outstripping the supply capacities of the planet, tough challenges may lie ahead in front of us (Diamond, 2005; Meadows et al., 1972; 2002). Sustainability plans are being made for many resources, which will become a necessary action in a crowded world (Bossel, 1998; Daily et al., 1994; Evans, 1998; Forrester, 1971; Green et al., 2003; Hirsch et al., 2005; Humphreys, 2003; Meadows et al., 1972; 2002; Ragnarsdottir et al., 2011b; Robert, 2000; Sachs, 2008; Sverdrup \& Rosen, 1998; Sverdrup et al., 2006; Zittel \& Schindler, 2007). Rare Earth Elements (REEs) are one resource group that play a key role in the transition to a new technological paradigm for the next century. The complete group of 17 REEs comprises the three elements Sc, Y and La, as well as the Lanthanide Elements, which are the 14 elements following La in the periodic table of the elements: Ce, Pr, Nd, Pm, Sm, Eu, Gd, Tb, Dy, Ho, Er, Tm, Yb and Lu (Enghag, 2004; IUPAC Recommendations 2005). Of the 17 REEs only one, Pm, is of little interest to industry since it has radioactive isotopes. Despite the name, REEs are not particularly rare in the earth's crust. Their combined crystal abundance is on the order $200 \mathrm{ppm}$ (Roskill Information service, 2007). Except for Pm, their individual abundance ranges from $0.5 \mathrm{ppm}$ for the least abundant, Tm, to $66 \mathrm{ppm}$ for the most abundant, Ce. The principal sources of the REEs are the minerals bastnäsite $\left(\mathrm{LnFCO}_{3}\right)$, monazite ( $\left.\mathrm{Ln}, \mathrm{Th}\right) \mathrm{PO}_{4}$ (richer in lighter lanthanides), xenotime (Y, Ln) $\mathrm{PO}_{4}$ (richer in the heavier lanthanides), loparite and the lateritic ion-adsorption clays (Cotton, 2006). The world's reserves of REEs are estimated to exceed 110 million tons (Emsley, 2003). However, the REEs are markedly dispersed in the 
planet's crust and, of the known 160 REE minerals, most are evenly distributed and thus unfeasible for extraction (Enghag, 2004). Initially, the main deposits were mined in India and Brazil but South Africa also began production in the 1950s, after the discovery of deposits of the mineral monazite there. From the mid-1980s, China starting growing into a position of dominance in the production of the REEs and, today, the country has a near monopoly of that market (Enghag, 2004; Roskill Information service, 2007).

The unique properties of REEs make them indispensable components of a wide range of emerging technologies and are of immense importance to technology for alternative-energy production. Hybrid cars, large wind turbines, catalytic converters, miniaturized electrical motors, compact magnets, rechargeable batteries, mobile phones, plasma televisions, super alloys used in defence industry, missiles and computer monitors are all dependent on the unique properties provided by the REEs. Interesting research is taking place in the area of catalysts for the chemical industry and a breakthrough here would signal a large new market with increased demand for these metals. Annual growth in demand for REEs from the technology industry is estimated to be somewhere between $8-11 \%$ (Roskill Information service, 2007). This means that the global supply of these materials is becoming as important as that of other commodities like oil, steel and coal.

\section{Scope and Objective}

In an earlier study, we investigated resource burn-off rates (time to scarcity) for phosphorous (Ragnarsdottir et al., 2011a; Sverdrup \& Ragnarsdottir, 2011). Burn-off rates are a simplistic approach indicating whether resources are being burned-off too quickly. In this study, we analyse the world's resource system for REEs and focus on the long-term sustainability and availability of these elements under different scenarios. Our aim is to understand sustainability constraints in order to help decision-making and future-planning in terms of the industry's ability to supply the market and the time horizons leading to scarcity. We address the following research questions:

1) How long will the world's REEs supply last under the present rate of use?

2) Is there any risk of "running out" of REEs for industry?

3) How much can supply be extended by enhanced recycling of all kinds?

This study adopts a long-term perspective, which envisions resource management that can bridge a civilization cycle of 5,000 years. We use 'short-term' to mean the next five to 30 years and 'long-term' to mean 30 to 300 years or many generations forward.

\section{Theory and Methods}

Systems analysis looks at complex setups by creating conceptual model structures with the help of Casual Loop Diagrams (CLD). CLDs make clear the cause-and-effect relationships and feedbacks between different components in a system. System dynamics is a methodology used to understand the behaviour of complex systems over time. It deals with internal feedback loops and time delays that affect the behaviour of the entire system. With the help of system dynamics, the conceptual model structures are transferred into dynamic numerical models, which can then be used as decision support tools by enabling the user to generate different scenarios and analyse the associated simulation results. Systems analysis and system dynamics provide a deep insight in identifying interdependencies and feedback processes of dynamic stocks and flows of materials, population dynamics and recycling-rates (Ragnarsdottir et al., 2011b).

The methods used here are systems analysis using a flow chart (Figure 1) and the corresponding casual loop diagram (Figure 2) according to (Haraldsson \& Sverdrup, 2004; Haraldsson et al., 2007). The system is based on two REE stocks, namely "known" and "hidden" reserves. The CLD shows the casual chain upon which the model was designed. Hidden reserves are never replenished, as they are finite. The known reserves may be replenished from hidden reserves through prospecting. Following the evaluation of the known reserves, accessible and inaccessible amounts for mining are determined. At present, the majority of the supply is from mining because recycling capacity is still limited. But, once the accessible reserves are exhausted, supply has to come from recycling alone. Prospecting, mining and recycling are all driven by market prices for REEs. New technological developments using REEs triggers increased demand and higher market prices, while more supply lowers prices and makes the increased use of new products possible. As industrial use takes off, waste generation and, in turn, recycling will increase. This market process for demand is described by the built CLD, which is then used as a conceptual map to develop a simulation model by applying the system-dynamics modelling software called STELLA. This model serves as a decision-support tool to assess alternative future scenarios for the long-term supply of REEs. 


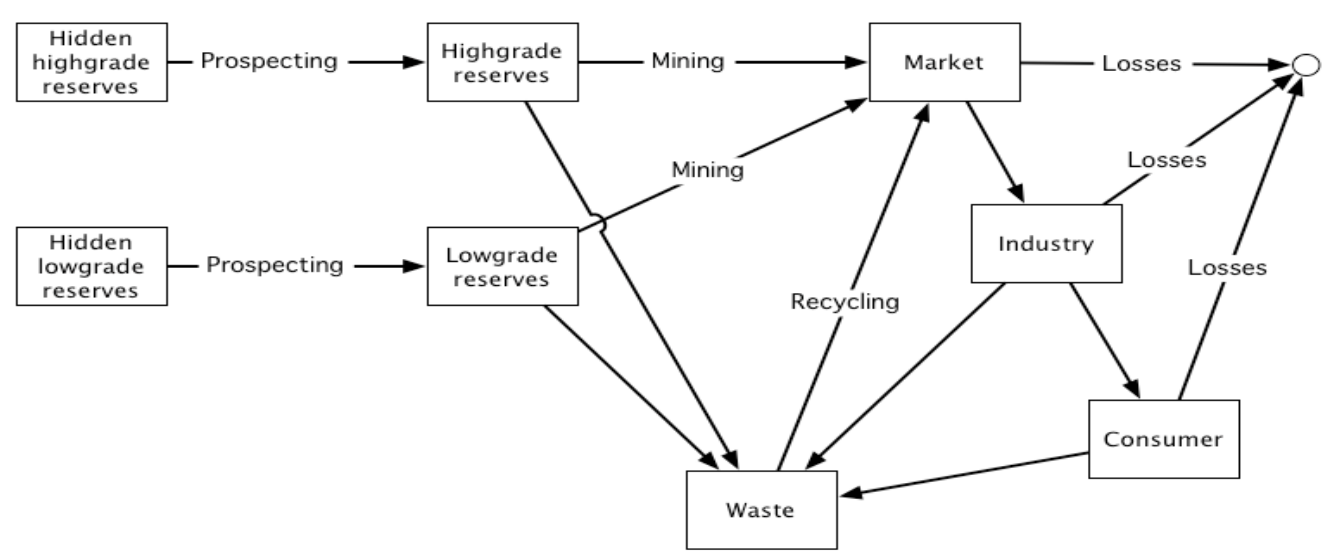

Figure 1. Material flow chart for the global REE system

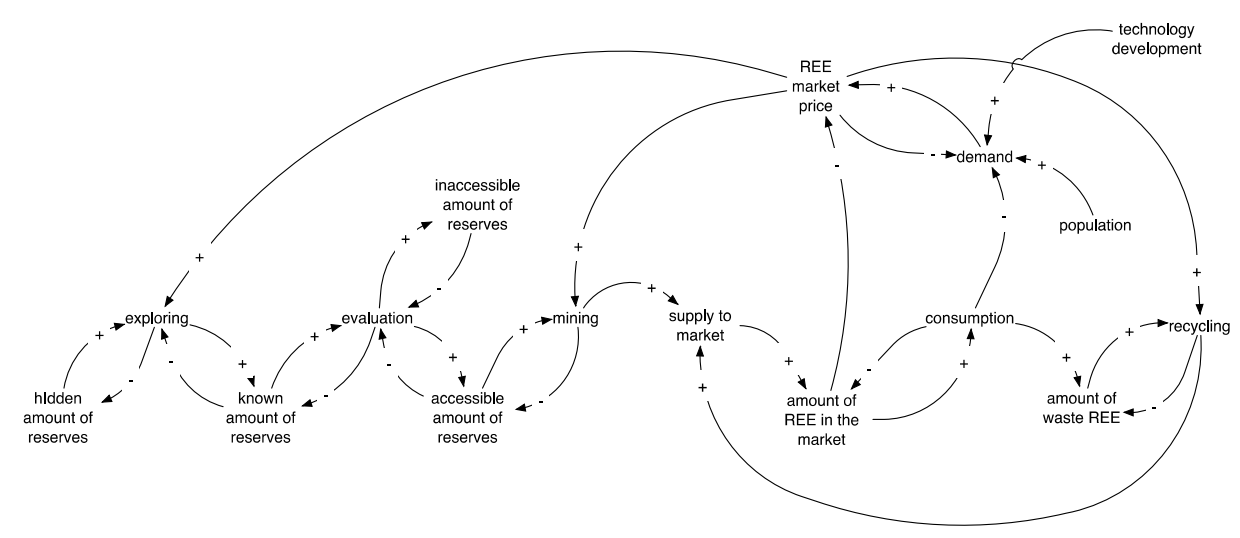

Figure 2. CLD for the REE system, showing the causal links operating in the mining and market system

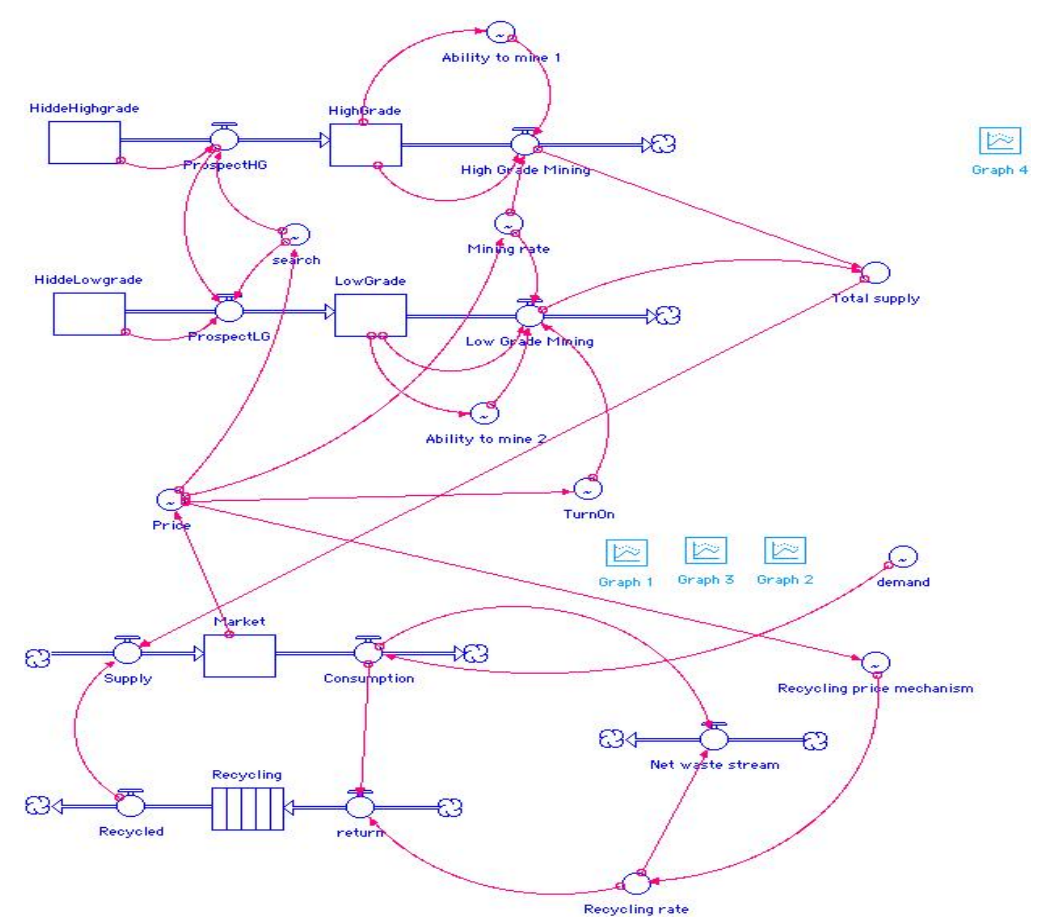

Figure 3. The STELLA model structure built based on the flow chart and the CLD in Figure 1 and 2, respectively 


\subsection{The STELLA Model}

We use outputs from dynamic simulations as the basis for our conclusions. The model (Figure 3) in the STELLA modelling environment was composed according to the flow chart in Figure 1 and the causal loop diagram in Figure 2. It describes the causal loops active in the system, showing several important feedback loops therein. We have two supply lines from which to mine, high-grade reserves and low-grade reserves, both divided into hidden reserves and known reserves. The low-grade mines are only worked when the REEs price is high. Further, we have the amount in the trading market as a stock. The recycling is also a stock because of the delay in processing it, whereas annual consumption and the annual waste stream are both done as fluxes. The system was set to run with a 2-step Runge-Kutta method, using a fixed numerical time-step of 0.1 years. We initially made printouts for every iteration step. The printouts, shown in Figure 5-7, have been taken directly from the STELLA system.

\subsection{Parameterization and Different Scenarios}

Dynamic models are developed and then used to estimate time to scarcity with and without recycling for different alternative scenarios. We define the time to scarcity as the time for the known reserve of high-grade and low-grade supply to have decreased to $10 \%$ of the original amount. The model was parameterized using data (Table 1-2) adopted from the following sources: Energy curves from the International Atomic Energy Agency (IAEA) www.iaea.organd the World Energy Outlook www.worldenergyoutlook.org homepage. Population estimates come from UN Population division homepage www.esa.un.org/wpp/ and Ragnarsdottir et al. (2011a). Data on known and estimated hidden reserves, as well as extraction rate, comes from USGS and Roskill information service Ltd reports.

Table 1. Approximation of the REEs demand trend

\begin{tabular}{llllll}
\hline Year & $\begin{array}{l}\text { Energy } \\
\text { Mtoe }^{\mathrm{a}}\end{array}$ & $\begin{array}{l}\text { People } \\
10^{9}\end{array}$ & $\begin{array}{l}\text { Energy available } \\
\text { Mtoe } / 10^{9} \text { persons }\end{array}$ & $\begin{array}{l}\text { Energy demand } \\
\text { Mtoe } / 10^{9} \text { persons }\end{array}$ & $\begin{array}{l}\text { Reserve/Deficit } \\
\text { Mtoe } / 10^{9} \text { persons }\end{array}$ \\
\hline 1950 & 4.00 & 2.5 & 1.60 & 1.59 & +0.01 \\
2000 & 10.0 & 6.1 & 1.65 & 1.65 & 0.00 \\
2010 & 12.9 & 6.8 & 1.89 & 1.89 & 0.00 \\
2020 & 12.0 & 7.5 & 1.60 & 1.89 & -0.29 \\
2040 & 10.0 & 8.6 & 1.17 & 1.89 & -0.72 \\
2100 & 3.0 & 9.46 & 0.32 & 1.89 & -1.57 \\
2200 & 2.5 & $10^{\mathrm{b}}$ & 0.25 & 1.89 & -1.62 \\
2400 & 2.4 & 10 & 0.24 & 1.89 & -1.65 \\
3000 & 1.8 & 10 & 0.18 & 1.89 & -1.71 \\
3300 & 1.5 & 10 & 0.15 & 1.89 & -1.74 \\
\hline
\end{tabular}

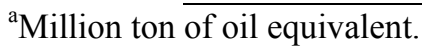

${ }^{\mathrm{b}} \mathrm{UN}$ projection is that the world population will stabilize at around 10 billion in the year 2200.

Table 2. Estimates of known and hidden REE reserves (Ragnarsdottir et al. 2011b, USGS 2008)

\begin{tabular}{llll}
\hline \multirow{2}{*}{ Item } & \multicolumn{3}{l}{ Initial REEs' amounts in the year $1950\left(10^{6}\right.$ tons $)$} \\
\cline { 2 - 4 } & Basic scenario & High estimates & Low estimates \\
\hline High-grade reserves & 40 & 80 & 17 \\
Hidden high-grade reserves & 100 & 200 & 20 \\
Low-grade reserves & 0 & 0 & 0 \\
Hidden low-grade reserves & 300 & 600 & 60 \\
Industry & 0 & 0 & 0 \\
Market & 0 & 0 & 0 \\
Total world inventory & 440 & 880 & 95 \\
Total extractable reserves $^{\mathrm{a}}$ & 230 & 460 & 55 \\
\hline
\end{tabular}

${ }^{a}$ We consider $100 \%$ of the high grade and $30 \%$ of the low grade reserves to be extractable 
As apparent from Table 1, demand is driven by the desire to remain at the 2010 energy supply level. When a deficit arises, more REEs go to alternative energy production. The increasing deficit after 2020 was used to set the shape of the demand curve. As they are predictions about the future, the demand projection is very approximate. Besides, we make some assumptions concerning the model. We do not divide up the REEs on individual elements, but model them in one lump parameter. Consumption increases demand for REEs, which in turn raises price. We have assumed recycling to be price sensitive and once REEs becomes scarce and expensive, recycling increases as shown in Figure 4A. We have also assumed the global population to remain at rather high levels, such as it is today, for the next millennium. The UN projects that the world population will stabilize at around 10 billion in the year 2200 , although a more recent projection suggests a decline in population. This alternative scenario will be addressed in our future work.

We may consider the Equations 1-3 expressing the relationship between consumption, consumers, consumption per person and the time to exhaustion of the resource.Increasing consumption and population are obviously the two major factors for an increase in demand for REEs. Increasing demand will increase mining rate, thereby hasten time to scarcity.As part of a sustainable production policy, recycling represents a way to increase REEs in the societal material cycle (market) without depleting resources, thereby decreasing mining rate and increasing time to scarcity (burn-off time).

Total consumption $=$ Consumption per individual/year * number of individuals consuming $[\mathrm{t} / \mathrm{yr}]$

Time to scarcity (without recycling) $=$ Reserve/mining rate [year]

Burn-off time (with recycling) $=$ Reserve/mining rate * $(1-\mathrm{R})$ [year]

Where: $\mathrm{R}$ is the recycling rate
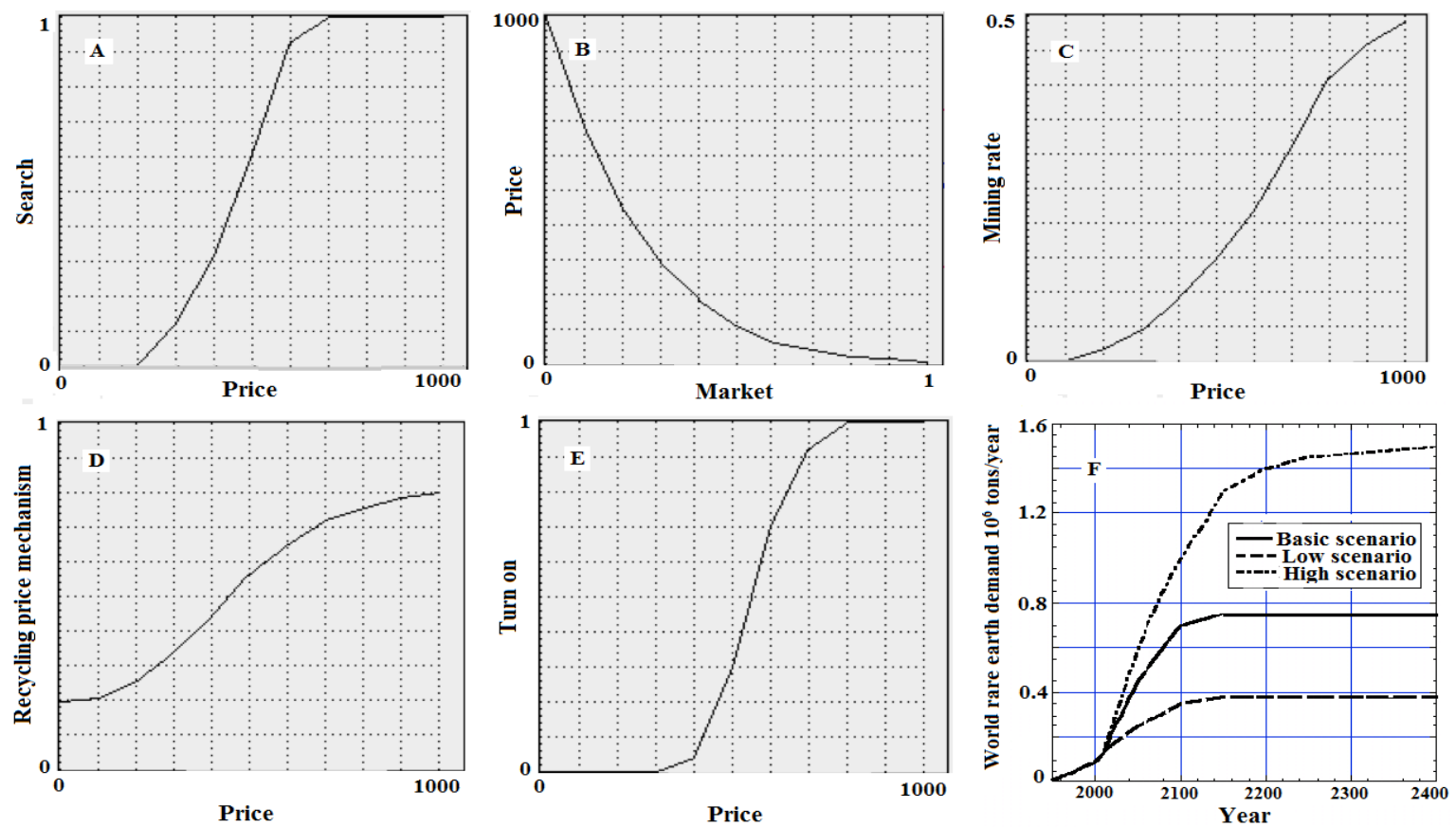

Figure 4. Factor interdependencies in the model. A: relationship between REEs' price and prospecting activity, B: the market price as a function of amount available in the market, $\mathrm{C}$ : the mining effort as a function of market price, D: the relationship between market price and degree of recycling, E: the relationship between market price for switching from high-grade to low-grade, $\mathrm{F}$ : the three demand scenarios considered, ramping up to $0.4 \times 10^{6}$

ton/year, $0.75 \times 10^{6}$ ton/year and $1.5 \times 10^{6}$ ton/year. Price dynamics were scaled from precious metal price-supply relationships (Sverdrup et al., 2012a \& b; Gordon et al., 2006). Note that the relationships are non-linear leading to a non-linear type of model output. 


\section{Results}

The results comprise back-of-the-envelope type of calculations as well as outputs from the integrated systems dynamic model developed for this study, and to be later included in the WORLD model structure (Ragnarsdottir et al., 2011b; Sverdrup et al., 2012a). We ran through several scenarios with the dynamic model for demand intensities. The different demand supply issues were dealt with by static equations. The model output results have been presented in a number of diagrams as shown in Figures 5-7.

\subsection{Basic Dynamic Model Runs}

Figure 5 shows the basic consumption-scenario dynamic model run (see Table 2). The upper panel shows REEs' price (arbitrary units), consumption and recycled amount, as well as net waste stream (in $10^{6}$ tons/year). The basic consumption run envisions that recycling is only price driven as specified in Figure 4D. The middle panel shows the mining-rates, the total supply-rate and the amount in the market. The bottom panel shows the REEs stocks, hidden and known, over time. The model outputs suggest that by $3100 \mathrm{AD}$ all REEs resources will be exhausted in the basic consumption calculations. The model output results show classical "peak" behaviour (Hubbert, 1982); the great scare of all Keynesian economists just like it has been shown for oil. The "peak" oil phenomenon has actually well proven beyond any reasonable doubt, and confirmed by most large oil company geologists (Aleklett, 2003; 2007; Hirsch et al., 2005; Hubbert, 1982; Ragnarsdottir et al., 2011a; Strahan, 2007; 2008). Peak behaviour implies that the production of a non-renewable resource follows systematically a bell-shaped curve; this is also called the Hubbert curve after K. Hubbert a petroleum geologist at the Shell Oil Corporation. Hubbert discovered the peak phenomenon in the oil industry, and could actually verify the validity on hard field data from oil, uranium and phosphorus extraction. It can also be explained in terms of causal chains and feedbacks and thus is both logical and proven principle (Ragnarsdottir et al., 2011b; Sverdrup et al., 2012a). The profitability of extracting REEs from the low grade reserves will be very sensitive to energy prices in the future, as large amounts of rock must be moved and mechanically processed. Without some form of cost-effective energy, these reserves will probably be largely unavailable. The model predictions show that the peak production year for the base consumption scenario is in the time around 2070-2080. Studies show that after 2100, fossil fuels will be scarce and expensive (Aleklett, 2003; 2007; Hirsch et al., 2005; Hubbert, 1982; Sverdrup et al., 2012b). The implication of this will be that low-grade reserves may become to a significant fraction unavailable for extraction.

\subsection{Recycling Scenario Based on Dynamic Run for High and Low Consumption Scenarios}

Figure 6 shows the high consumption estimate scenario for the period from 1950 to 2400 AD. The upper diagram shows the REEs price (arbitrary unit), consumption and recycling rates, as well as the amount of REEs in the market, all in million tons per annum. The middle panel shows mining-rates and market-flux in million tons of REEs per annum. The lower panel shows the development of the resource stocks. The simulations show that the peak production year is about $2250 \mathrm{AD}$. By $2600 \mathrm{AD}$ (out of shown range), the mineable stocks will be almost empty, and the single source will be from recycling of waste. It can be seen that the effect of increased recycling is to keep the market supplied and the price within reasonable ranges. From the middle panel is it evident that recycling decreases the mining-rates, making the resources available to last longer. The point of exhaustion has now been delayed with approximately 150 years.

Figure 7 shows the low consumption scenario for the time from 1950 to 2400 AD.The upper panel shows the REEs price (arbitrary unit), consumption and recycling rates, as well as the amount of REEs in the market, all in million tons per annum. The middle diagram shows mining-rates and market-flux in million tons of REEs per annum. The lower panel shows the development of the resource stocks. Maximum production is reached in 2070, but it will remain there for the next centuries, thanks to recycling. The decline is from then on dependent on how efficient the recovery can be made. By the year $5400 \mathrm{AD}$ (outputs are not shown), the mineable stocks in the ground will be almost empty, and the single source will be recycling of waste. 
Basic consumption scenario curves
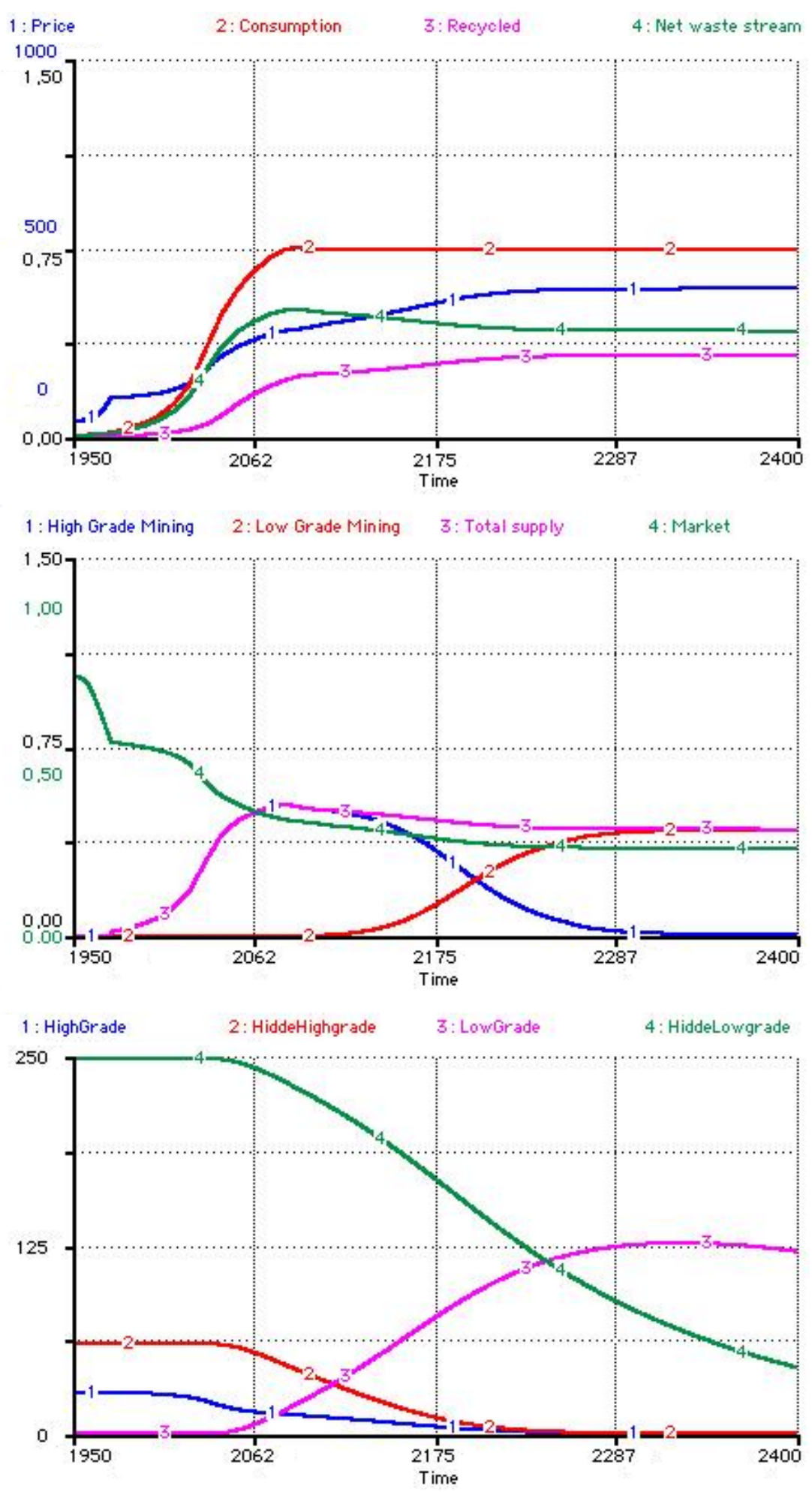

Figure 5. Basic consumption run, showing REEs' price (arbitrary unit), market consumption, and amount recycled and net waste stream (all in $10^{6}$ ton/year) in the first panel. The basic consumption run envisions that recycling is only price driven in this calculation. The middle panel shows the mining-rates, the total supply-rate and the amount in the market. The bottom panel shows the REEs stocks, hidden and known over time. It can be seen that by $2400 \mathrm{AD}$ all REEs resources in the ground will have been exhausted 
High consumption scenario curves
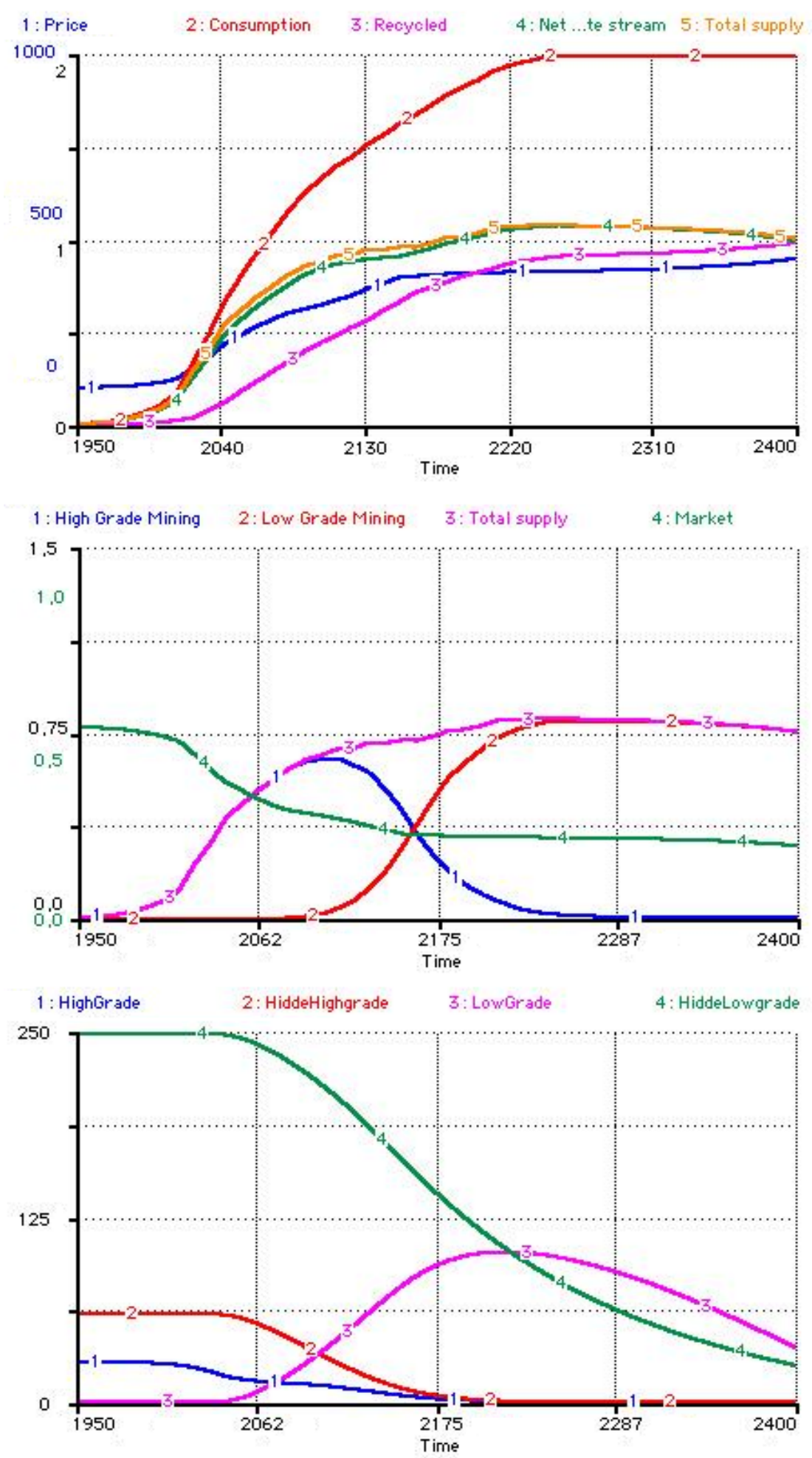

Figure 6. The high consumption scenario:The upper diagram upper shows REE price with time from 2000 to $2400 \mathrm{AD}$. The flow rates consumption and recycled in $10^{6}$ ton/year, are shown and the amount REEs in the market. Recycling is now enforced. The middle panel shows mining rates and market flux in $10^{6}$ tons of REEs per year. The bottom panel shows the development of the resource stocks (million tons). By the time of $2250 \mathrm{AD}$, the mineable stocks will be almost empty, and the single source of REE material will be from recycling waste 
Low consumption scenario curves
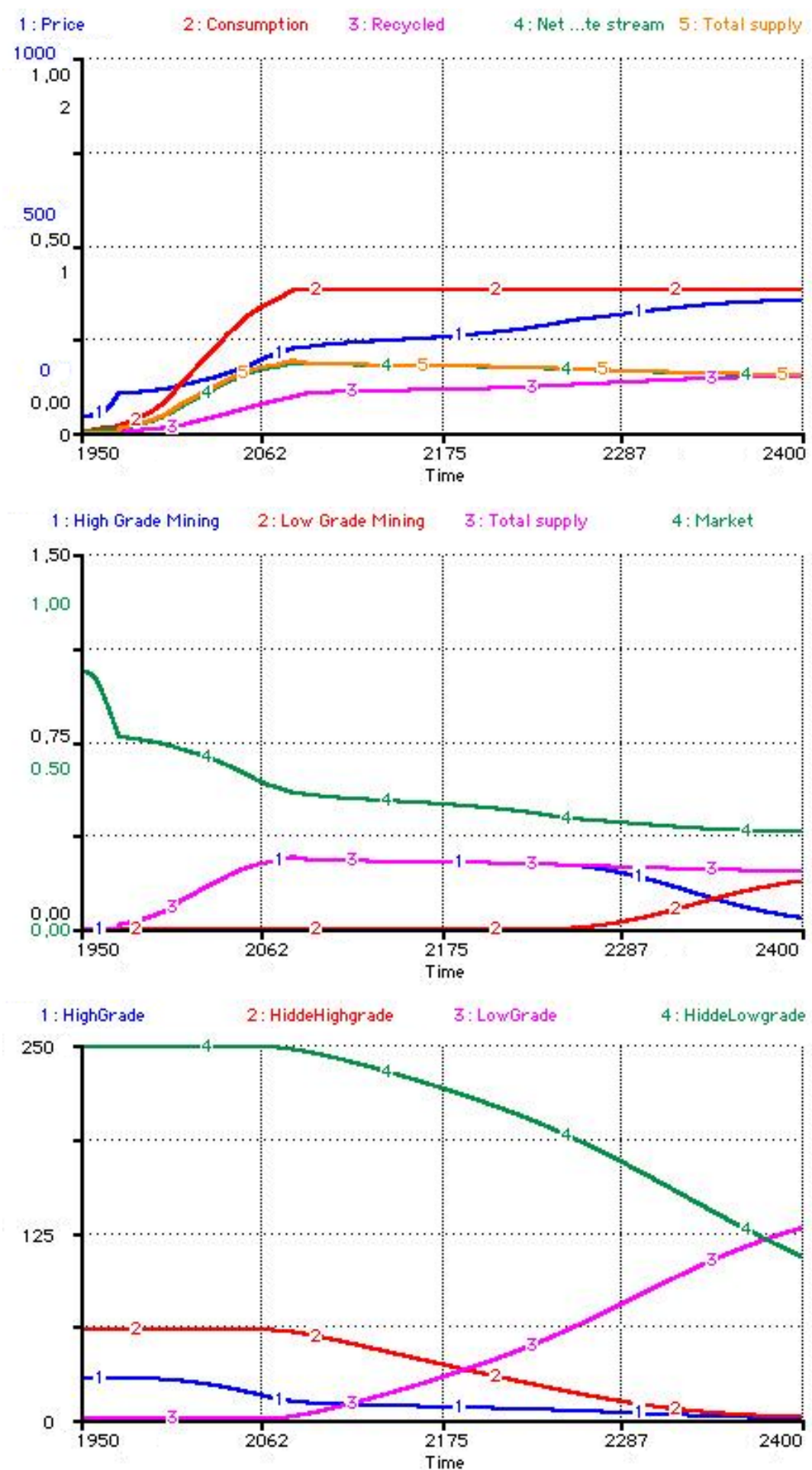

Figure 7. The low consumption scenario: The upper diagram shows REE price with time from 2000 to 2400 AD. The flow rates consumption and recycled in $10^{6}$ ton/year, are also shown and the amount REEs in the market. Recycling is now enforced. The middle panel shows mining-rates and market flux in $10^{6}$ tons of REEs per year. The bottom panel shows the development of the resource stocks $\left(10^{6}\right.$ tons). By the year $5400 \mathrm{AD}$ (outputs are not shown), the mineable stocks will be almost empty and the single source of REE material will be from recycling waste 


\subsection{Recycling Scenarios Based on Steady State Mass Balance Calculations}

Table 3 shows some of our burn-off time estimates for different reserve estimates and market consumption-rates. It shows that for a low reserve estimate, there is a real risk of running into REEs scarcity, implying that they will get expensive.

Table 3. Burn-off time estimates for different reserve estimates and market consumption rates (USGS 2008)

\begin{tabular}{llll}
\hline \multirow{2}{*}{$\begin{array}{l}\text { REE consumption } \\
\left(10^{6} \text { ton/year }\right)\end{array}$} & $\begin{array}{l}\text { High reserve estimate } \\
\left(460 \times 10^{6} \text { ton }\right)\end{array}$ & $\begin{array}{l}\text { Base reserve estimate } \\
\left(230 \times 10^{6} \text { ton }\right)\end{array}$ & $\begin{array}{l}\text { Low reserve estimates } \\
\left(55 \times 10^{6} \text { ton }\right)\end{array}$ \\
\cline { 2 - 4 } & \multicolumn{3}{c}{ Burn-off time in years } \\
\hline 0.400 & 1150 & 575 & 138 \\
0.750 & 613 & 306 & 73 \\
1.500 & 307 & 153 & 37 \\
\hline
\end{tabular}

By a simple rearrangement of a mass balance for supply and loss, we get the equations used for creating Table 4 . The improvement that can be obtained with recycling is expressed through the Equations 4-6:

$$
\text { Market availability (supply rate) }=\text { Primary production rate * }(1+\mathrm{R} /(1-\mathrm{R})) \text { [ton/year] }
$$

This may be rearranged to the inverse, for back-engineering purposes:

$$
\text { Primary production }(\text { loss rate })=\text { Market availability } /(1+\mathrm{R} /(1-\mathrm{R})) \text { [ton/year] }
$$

This may be rearranged into an equation estimating the required recovery-rate from waste if a certain supply rate in the market is to be achieved:

$$
\mathrm{RR}=\text { (market availability- primary production) } / \text { (market availability }+ \text { primary production) }
$$

Where: $\mathrm{R}$ is the recycling-rate and $\mathrm{RR}$ is the required recovery-rate in relationship to a certain basic supply and market consumption level.

From the dynamic modelling, we estimate the depletion time for the resource to be in the order of 400 years for the basic run. This is consistent with results from the literature (Ragnarsdottir et al., 2011b; Sverdrup et al., 2012a). Present recycling of REEs is estimated to be about $10 \%$ at the moment. We used this information to estimate the effect of different recycling rates on the ability to serve the market from a dwindling source as presented in Table 4 . It is evident that recycling will be very important for the long-term sustainability of REEs used for industrial purposes. Table 4 also assumes the population remains at the samelevel as the present. How long the resource will last, depend on the recycling and the market demand.

Table 4. The effect of different recycling rates on the ability to serve the market from a dwindling source

\begin{tabular}{llll}
\hline $\begin{array}{l}\text { Recycling rates }^{\mathrm{a}} \\
(\%)\end{array}$ & $\begin{array}{l}\text { Market availability rate } \\
\left(10^{6} \text { ton/year }\right)\end{array}$ & $\begin{array}{l}\text { Primary production }^{\mathrm{c}} \\
\left(10^{6} \text { ton/year }\right)\end{array}$ & $\begin{array}{l}\text { Business life of REE resource }^{\mathrm{d}} \\
(\text { year })\end{array}$ \\
\hline 10 & 0.167 & 0.150 & 400 \\
25 & 0.200 & 0.125 & 480 \\
50 & 0.300 & 0.075 & 800 \\
75 & 0.600 & 0.038 & 1600 \\
85 & 1.000 & 0.023 & 2700 \\
90 & 1.700 & 0.017 & 3600 \\
\hline
\end{tabular}

${ }^{a}$ Recycling rates applied on primary production.

${ }^{b}$ Market availability assuming constant supply from the primary source, but changing recycling.

${ }^{c}$ Required primary supply to keep market availability at $0.167 \times 10^{6}$ ton/year with changing degree of recycling.

${ }^{\mathrm{d}}$ The increased lifetime of the primary supply, assuming constant consumption and changing recycling-rate. 


\section{Reflections}

The REEs may be abundant on earth, but the present global consumption pattern and population size is capable of outrunning almost any capacity of resource production. Thus it is apparent that the REEs reserves will not last forever. Recycling seems to be a very important part of any sustainability plan. If other assumptions are made for global population, resulting in significant lower population levels after the next 500-700 years (2-3 billion), then the picture looks very different. With strongly price-related recycling, the reserves of REEs would probably last about 5,500 years according to the outputs from the dynamic model. An assessment of what it would take in terms of mandatory recycling to make the resource last 2,000 years under different consumption scenarios is shown in Table 5 .

Table 5. An assessment of mandatory recycling under different consumption scenarios to make the REE resource last 2000 years

\begin{tabular}{lll}
\hline $\begin{array}{l}\text { Market supply } \\
\left(10^{6} \text { ton/year }\right)\end{array}$ & $\begin{array}{l}\text { Recycling required }^{\mathrm{b}} \\
(\%)\end{array}$ & $\begin{array}{l}\text { Average efficiency }^{\mathrm{c}} \\
(\%)\end{array}$ \\
\hline 0.200 & 27 & 65 \\
0.400 & 55 & 82 \\
0.800 & 75 & 91 \\
1.600 & 87 & 96 \\
3.200 & 93 & 97.6 \\
6.400 & 96 & 98.7 \\
\hline
\end{tabular}

${ }^{\text {a }}$ Supply of REEs to the market in million ton per year.

${ }^{\mathrm{b}}$ The required overall recycling rates.

${ }^{\mathrm{c}}$ The required average efficiency in an industrial recovery process.

We are assuming the total resource to be exploitable to $100 \%$ of the high-grade and $30 \%$ of the low-grade, we have a total resource of 230 mill ton of REEs. A primary extraction of 115,000 tons/yr will be available under these assumptions. Recycling processes involve several steps when done industrially, each demanding a good efficiency. We have assumed to consider a 3-step recovery process for the REEs based on our professional experience from the recovery industry. Single step efficiencies above $95 \%$ demand expensive operations and represent a major technical challenge. Precious metals operate on the overall efficiency rate of $95-98 \%$ in the recovery process. That kind of recovery-rate requires significant energy expenditure and will still be a huge technical challenge. This is corroborated by the simple back-of-the-envelope calculations shown in Table 3 and 4, estimating a lifetime of the resource into thousands of years once the recycling-rate reaches levels of $60 \%$ or better.

One reflection on the system is shown in Figure 8, where we have incorporated some possible policy interventions (marked in red) into the REE market system that we previously presented in Figure 2. Many policy options are available in order to use less REEs to do more services. Interventions can be made to create more efficient alternative technologies, stimulate more recycling, make waste disposal with recycling more attractive, interventions on price and interventions on the extractions-rates. Market mechanisms alone are, quite evidently, not capable of regulating the market towards more efficient use before it appears to be too late. Thus leaving the management of sustainable use to free market forces will be inadequate, as the triggering price-increase will only happen when a majority of the resource has been consumed and probably irretrievably squandered. This is because market mechanisms only measure the availability in the instant (based on market-price) without any significant foresight and no long-term strategic planning. The market has no memory and no capacity for long-term planning: this must rather be the responsibility of state governance agents through policy and legislation. For a limited resource with limited substitutability, this is far from good enough, especially if we stake our future with new technologies on it (Ragnarsdottir et al., 2011b; Sverdrup et al., 2012b). Thus market mechanisms must always be combined with regulations and governance based on back-casting from goals (Robert, 2000) and future analysis of scenarios, in order to instigate sustainable recycling practices long before scarcity is at all an issue. This necessitates a change of the present public use-and-throw paradigm, as well as the political paradigm, where planning a century ahead will be a major part of a long-term survival strategy for the 
state. For this kind of strategically important resources, a precautionary policy will be necessary to preserve availability for future generations. This will imply arranging for a high degree of recycling, before market mechanisms are able to force it through standard price dynamics.

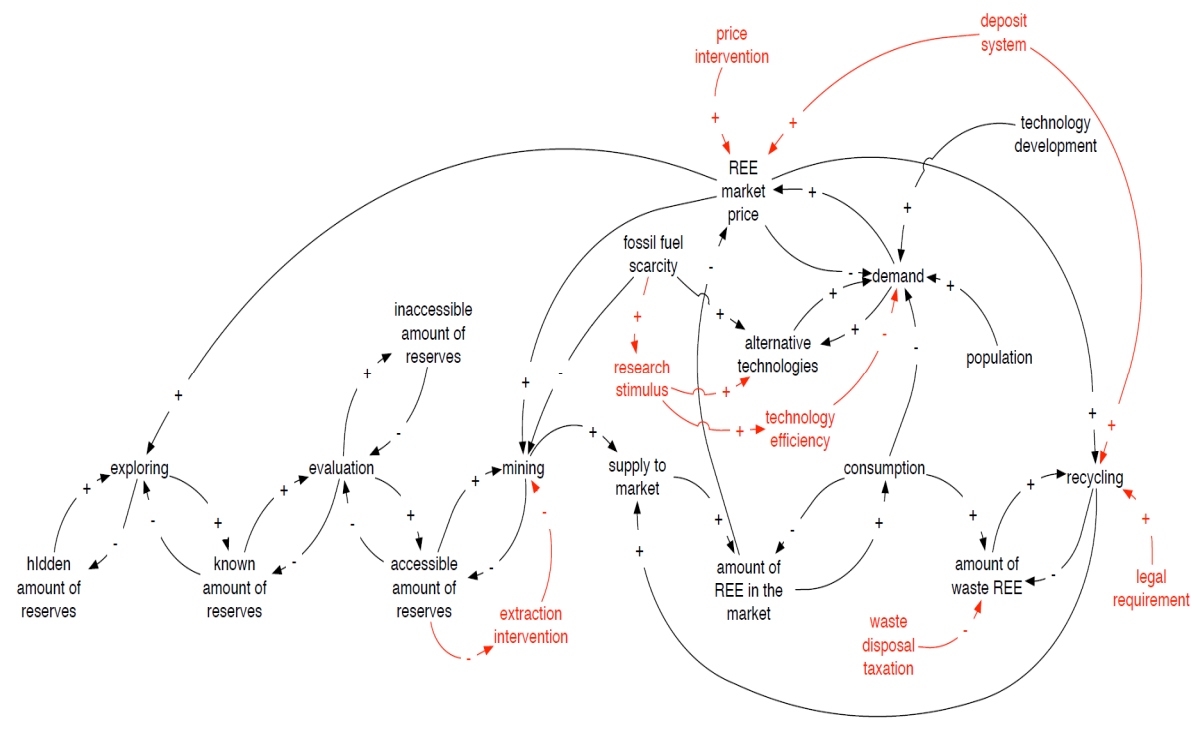

Figure 8. The REE market mechanisms and potential policy interventions drawn in red to qualitatively increase long term supply capabilities. One important tool is efforts to enhance recycling and recovery from waste

\section{Conclusions}

We may conclude that the Earth's resources of REEs will not last forever, hardly a controversial statement. The time horizon of 2000 years seems very long in a political perspective, but a bit short in terms of a historical perspective. In our assumptions, we have supposed a high global population (the baseline IIASA scenario) and thus the pressure on consumption will be large in the time to come. For the short-term (5-30 years), the global reserves of REEs seem to be sufficient for the immediate needs of the market. For the long-term (30-300 years), there will be an issue with long-term sustainability; leading to the conclusion that this can be prevented by policies that result in increased recycling from waste. There is some uncertainty in the reserve estimates, and whereas the situation is unsustainable in the short run of a small reserve estimate is true, there will be less urgency for achieving sustainable use under a high reserve estimate scenario.

\section{Acknowledgements}

This study was funded by K A Rasmussen AS, Hamar, Norway, Thor Technologies AS, Oslo, Norway, and the Norwegian Research Council, Oslo, Norway. The work of Dr. Deniz Koca was financed by the European Union CONVERGE program through Lund University, Lund, Sweden. The authors are grateful to the anonymous reviewers whose comments and suggestions significantly improved both clarity and precision of the paper. The authors acknowledge the help of Mr. Darrin Griggs in proof reading and editing the manuscript.

\section{References}

Aleklett, K. (2003). The Peak and Decline of World Oil and Gas Production. Journal of Minerals and Energy, 18, 5-20. http://dx.doi.org/10.1080/14041040310008374

Aleklett, K. (2007). Peak oil and the evolving strategies of oil importing and exporting countries, Discussion paper 17 to Joint Transport Research Centre - OECD - International Transport Forum.

Beder, S. (2000). Costing the earth: Equity: Sustainable development and environmental economics. New Zealand Journal of Environmental Law, 4, 227-243.

Bossel, H. (1998). Earth at the crossroads: Paths to a sustainable future. Cambridge University Press.

Costanza, R., \& Daly, H. E. (1992). Natural capital and sustainable development. Conservation Biology, 6, 1-10. http://dx.doi.org/10.1046/j.1523-1739.1992.610037.x 
Cotton, S. (2006). Lanthanide and Actinide chemistry. London: John Wiley \& Sons Ltd. http://dx.doi.org/10.1002/0470010088

Daily, G. C., \& Ehrlich, P. (1992). Population, sustainability and the Earth's carrying capacity: A framework for estimating population sizes and lifestyles that could be sustained without undermining future generations. Journal of Bioscience, 42, 761-771. http://dx.doi.org/10.2307/1311995

Daily, G. C., Ehrlich, A. H., \& Ehrlich, P. R. (1994). Optimum human population size, Population and environment. A Journal of Interdisciplinary Studies, 15, 469.

Diamond, J. (2005). Collapse: How societies choose to fail or survive. London: Penguin Books.

Emsley, J. (2003). Nature's Building Blocks: An A-Z guide to the elements. Oxford: Oxford University Press.

Enghag, P. (2004). Encyclopaedia of the Elements: Technical Data, History, Processing, Application. Weinheim, WILEY-VCH Verlag GmbH \& Co KGaA.

Forrester, J. (1971). World dynamics. Waltham MA: Pegasus Communications.

Gordon, R., Bertram, B., \& Grädel, M. (2006). Metal stocks and sustainability. Proceedings of the National Academy of Science, 103, 1209-1204. http://dx.doi.org/10.1073/pnas.0509498103

Greene, D. L., Hopson, J. L., \& Li, J. (2003). Running out of and into oil: Analyzing global depletion and transition through 2050. Oak Ridge National Laboratory, Oak Ridge, Tennessee ORNL/TM-2003/259.

Haraldsson, H. V., \& Sverdrup, H. U. (2004). Finding simplicity in complexity in biogeochemical modelling. In J. Wainwright \& M. Mulligan (Eds.), Environmental modelling: A practical approach (pp. 211-223). Chichester: J. Wiley and Sons Ltd.

Haraldsson, H., Sverdrup, H., Belyazid, S., Holmqvist, J., \& Gramstad, R. (2007). The tyranny of small steps: A reoccurring behaviour in management. Journal of Systems Research and Behavioral Science, 24, 1-19.

Hirsch, R. L., Bezdek, R., \& Wending, R. (2005). Peaking of world oil production: Impacts, mitigation and risk management. Retrieved from www.netl.doc.com/publ/other/pdf/oil_publ_net/pdf/

Hubbert, M. K. (1982). Techniques of prediction as applied to production of oil and gas. United States Department of Commerce, NBS Special Publication 631, May 1982.

Humphreys, M., Sachs, J., \& Stiglitz, J. (2003). Escaping the resource curse. Columbia: Columbia University Press. International atomic energy (IAEA) home page, www.iaea.org.

Meadows, D. H., Meadows, D. L., Randers, J., \& Behrens, W. (1972). Limits to growth. New York, NY: Universe Books.

Meadows, D. H., Randers, J., \& Meadows, D. (2002). Limits to growth: The 30 year updates. New York, NY: Universe Press.

Ragnarsdottir, K. V., Sverdrup. H., \& Koca, D. (2011a). Challenging the planetary boundaries-I: Basic principles of an integrated model for the phosphorous supply dynamics and global population size. Applied Geochemistry, 26, 311-313. http://dx.doi.org/10.1016/j.apgeochem.2011.03.088

Ragnarsdottir, K. V., Sverdrup. H., \& Koca, D. (2011b). Assessing long-term sustainability of global supply of natural resources and materials. In C. Ghenai (Ed.), Sustainable development, energy, engineering and technologies- manufacturing and environment (Chapter 5; pp. 83-116).

Robèrt, K.-H. (2000). Tools and concepts for sustainable development: How do they relate to a framework for sustainable development, and to each other? The Journal of Cleaner Production, 8, 243-254. http://dx.doi.org/10.1016/S0959-6526(00)00011-1

Roskill Information Services Ltd. (2007). The economics of rare earths and yttrium (13th ed.). Sydney.

Sachs, J. (2008). Common Wealth: Economics for a Crowded Planet. London: Penguin Press.

Strahan, D. (2007). The Last Oil Shock: A survival guide to the imminent extinction of petroleum man. New York, NY: John Murray Books.

Strahan, D. (2008). Coal: Bleak outlook for the black stuff. New Scientist, 2639, 38-41. http://dx.doi.org/10.1016/S0262-4079(08)60173-6

Sverdrup, H., \& Rosen, K. (1998). Long term base cation mass balances for Swedish forests and the concept of sustainability. Forest Ecology and Management, 110, 221-236. http://dx.doi.org/10.1016/S0378-1127(98)00283-7 
Sverdrup H., \& Svensson, M. (2002). Defining the concept of sustainability, a matter of systems analysis. In M. Olsson \& G. Sjöstedt (Eds.), Revealing complex structures - Challenges for Swedish systems analysis (pp. 122-142). New York, NY: Kluwer Academic Publishers.

Sverdrup, H., Thelin, G., Robles, M., Stjernquist, I., \& Sörensen, J. (2006). Assessing sustainability of different tree species considering $\mathrm{Ca}, \mathrm{Mg}, \mathrm{K}, \mathrm{N}$ and $\mathrm{P}$ at Björnstorp Estate, Biogeochemistry, 81, 219-238. http://dx.doi.org/10.1007/s10533-006-9038-2

Sverdrup, H., Koca D., \& Ragnarsdottir, K. V. (2011). Challenging the planetary boundaries II: Assessing the sustain global population and phosphate supply using a systems dynamics assessment model. Applied Geochemistry, 26, 311-313. http://dx.doi.org/10.1016/j.apgeochem.2011.03.089

Sverdrup, H., Koca, D., \& Ragnarsdottir, K. V. (2012a). The world model: Peak metals, minerals, energy, wealth, food and population; urgent policy considerations for a sustainable society. In M. Schwanninger, E. Husemann, \& D. Lane (Eds.), Proceedings of the $30^{\text {th }}$ International Conference of the System Dynamics Society of St. Gallen, Switzerland, July 22-26, 2012, Model-based management (pp. 1-27). University of St. Gallen, Switzerland; Systems Dynamics Society.

Sverdrup, 'H., Koca, D., \& Granath, C. (2012b). Modeling the gold market: Explaining the past and assessing the physical and economical sustainability of future scenarios. In M. Schwanninger, E. Husemann \& D. Lane (Eds.), Proceedings of the $30^{\text {th }}$ International Conference of the System Dynamics Society of St. Gallen, Switzerland, July 22-26, 2012 Model-based management (pp. 1-28). University of St. Gallen, Switzerland; Systems Dynamics Society.

Turner, G. (2008). A comparison of the limits to growth with thirty years of reality. Socio-economics and the environment in discussion. CSIRO Working papers, Series 2008-2009.

United States Geological Survey (USGS) website. (2008). Commodity statistics for a number of metals.

World Energy Outlook Home Page www.worldenergyoutlook.org.

Zittel, W., \& Schindler, J. (2007). Coal resources and future production: A background paper produced by the Energy Watch Group. Ottobrunn. Ludwig Bolkow Foundation.

\section{Appendix}

Complete set of model equations in STELLA syntax

HiddeHighgrade $(\mathrm{t})=$ HiddeHighgrade $(\mathrm{t}-\mathrm{dt})+(-$ ProspectHG $) * \mathrm{dt}$

INIT HiddeHighgrade $=100$

\section{OUTFLOWS:}

ProspectHG $=$ HiddeHighgrade $*$ search $* 0.1$

HiddeLowgrade $(\mathrm{t})=$ HiddeLowgrade $(\mathrm{t}-\mathrm{dt})+(-$ ProspectLG $) * \mathrm{dt}$

INIT HiddeLowgrade $=250$

\section{OUTFLOWS:}

ProspectLG $=$ ProspectHG*0.2+HiddeLowgrade*search*0.02

HighGrade $(\mathrm{t})=$ HighGrade $(\mathrm{t}-\mathrm{dt})+($ ProspectHG - High_Grade_Mining $) * d t$

INIT HighGrade $=28$

INFLOWS:

ProspectHG $=$ HiddeHighgrade search $^{*} 0.1$

\section{OUTFLOWS:}

High_Grade_Mining $=$ HighGrade*Mining_rate*Ability_to_mine_1

LowGrade $(\mathrm{t})=$ LowGrade $(\mathrm{t}-\mathrm{dt})+($ ProspectLG - Low_Grade_Mining $) * d t$

INIT LowGrade $=0$

INFLOWS:

ProspectLG $=$ ProspectHG*0.2+HiddeLowgrade* ${ }^{*}$ earch $* 0.02$

OUTFLOWS: 
Low_Grade_Mining $=$ TurnOn*Mining_rate*LowGrade*Ability_to_mine_2

$\operatorname{Market}(\mathrm{t})=\operatorname{Market}(\mathrm{t}-\mathrm{dt})+($ Supply - Consumption $) * d t$

INIT Market $=0.001$

INFLOWS:

Supply = Recycled+Total_supply

OUTFLOWS:

Consumption $=$ demand

$\operatorname{Recycling}(\mathrm{t})=\operatorname{Recycling}(\mathrm{t}-\mathrm{dt})+($ return - Recycled $) * d t$

INIT Recycling $=0$

TRANSIT TIME $=10$

INFLOW LIMIT $=\infty$

CAPACITY $=\infty$

INFLOWS:

return $=$ Consumption*Recycling_rate

OUTFLOWS:

Recycled $=$ CONVEYOR OUTFLOW

UNATTACHED:

Net_waste_stream $=$ Consumption*(1-Recycling_rate $)$

Ability_to_mine_1 $=$ GRAPH(HighGrade)

(0.00, 0.00), (0.1, 0.01), (0.2, 0.095), (0.3, 0.28), (0.4, 0.675), (0.5, 0.895), (0.6, 1.00), (0.7, 1.00), (0.8, 1.00), $(0.9,1.00),(1,1.00)$

Ability_to_mine_2 $=$ GRAPH(LowGrade)

$(0.00,0.00),(2.00,0.005),(4.00,0.03),(6.00,0.105),(8.00,0.275),(10.0,0.45),(12.0,0.685),(14.0,0.845)$, $(16.0,0.95),(18.0,0.99),(20.0,1.00)$

demand $=$ GRAPH(TIME)

(1950, 0.00), (2038, 0.135), (2125, 0.29), (2212, 0.43), (2300, 0.605), (2388, 0.69), (2475, 0.73), (2562, 0.755), (2650, 0.74), (2738, 0.7), (2825, 0.65), (2912, 0.6), (3000, 0.56)

Mining_rate $=$ GRAPH $($ Price $)$

(0.00, 0.00), (100, 0.0015), (200, 0.027), (300, 0.054), (400, 0.1), (500, 0.143), (600, 0.21), (700, 0.31), (800, 0.393), (900, 0.448), (1000, 0.475)

Price $=$ GRAPH $($ Market $)$

$(0.00,995),(0.1,680),(0.2,445),(0.3,290),(0.4,185),(0.5,110),(0.6,80.0),(0.7,60.0),(0.8,60.0),(0.9,60.0)$, $(1,55.0)$

Recycling_price_mechanism $=$ GRAPH(Price)

(0.00, 0.195), (100, 0.205), (200, 0.255), (300, 0.34), (400, 0.44), (500, 0.56), (600, 0.65), (700, 0.72), (800, 0.755), (900, 0.785), (1000, 0.8)

Recycling_rate $=$ Recycling_price_mechanism

search $=$ GRAPH(Price)

(0.00, 0.00), (100, 0.00), (200, 0.005), (300, 0.12), (400, 0.315), (500, 0.605), (600, 0.93), (700, 1.00), (800, $1.00),(900,1.00),(1000,1.00)$

Total_supply $=$ High_Grade_Mining+Low_Grade_Mining

TurnOn $=$ GRAPH(Price)

(0.00, 0.00), (100, 0.00), (200, 0.00), (300, 0.00), (400, 0.04), (500, 0.295), (600, 0.7), (700, 0.925), (800, 1.00), $(900,1.00),(1000,1.00)$ 